\title{
Willingness to Move for Work and Unemployment Duration in Spain
}

\author{
Namkee Ahn \\ CEMFI \\ Sara de la Rica \\ Universidad del País Vasco \\ Arantza Ugidos \\ Universidad del País Vasco
}

Working Paper No. 9801

April 1998

We are grateful for comments from the seminar participants at the University of the Basque Country (Bilbao) and CEMFI (Madrid), and for financial support from the Spanish Ministry of Education (DGICYT PB94-1372), the Basque Government (PI95/14) and the University of the Basque Country (UPV 035.321-HB 230/95). We also wish to thank Luis Toharia for providing us with the dataset. (E-mail addresses: namkee@cemfi.es, jeprigos@bs.ehu.es, jepugola@bs.ehu.es).

CEMFI, Casado del Alisal 5, 28014 Madrid, Spain.

Tel: 341 4290551, fax: 341 4291056, www.cemfi.es. 


\begin{abstract}
This paper examines unemployed workers' willingness to move for work and its relationship with their unemployment duration in Spain. We use a hypothetical question in the Spanish Labour Force Survey: "Would you accept a job offer which implied a change of residence?". The main finding is that while family responsibilities, age and education are important in determining individuals' migration willingness, the duration of unemployment does not show any significant effect, even after controlling for unobserved fixed individual heterogeneity. However, the significant improvement in migration willingness after exhaustion of unemployment benefits (or when other household members become unemployed) suggests that economic incentives could play an important role in increasing worker mobility. We also find that the job-finding probability is significantly higher among those with positive migration attitudes than among others.
\end{abstract}




\section{INTRODUCTION}

The high unemployment rate in Spain has caused much debate in recent years, not only among policy makers but also among economists. Among the reasons most often cited for this are insufficient job creation from the labour demand side resulting in high structural unemployment (Bentolila and Blanchard, 1990), and generous unemployment benefit and family support from the labour supply side (Ahn and Ugidos, 1995; Toharia and Jimeno, 1995). Also pointed out as a potential reason for high unemployment is the extremely low regional migration rate in spite of the persistent regional differences in income and unemployment rates (Antolin and Bover, 1997; Bentolila, 1997; Jimeno and Bentolila, 1995). According to Antolin and Bover (1997), during the period 1987-1991, only 0.295\% of Spanish men, aged 16 to 70, who were in the labour force changed their region of residence over a one year period. The studies cited above do not find any relationship between migration rates and unemployment rates across regions.

This paper examines another aspect of labour supply to further understand the Spanish unemployment problem. It examines unemployed workers' willingness to move for work and its relationship with their unemployment duration in $\operatorname{Spain}^{1}$. The topic has not drawn much attention so far due to the lack of data and partly due to the reluctance of economic researchers to use attitudinal variables ${ }^{2}$. Exceptions are the studies by Hughes and McCormick (1985) and Faini et al. (1997). The former examines the effect of regional and individual unemployment on individuals' migration intention in Great Britain while the latter studies a similar question to ours for the case of Italy. The former study finds that unemployment (especially among nonmanual workers) increases workers' movement/migration intention, and the longer the duration the stronger the effect, and the latter concludes that low mobility among Italian youth is due to inefficiencies in the interregional job-matching process and high mobility costs. In Spain,

${ }^{1}$ Unfortunately, in the survey which we use the question regarding the willingness to move is addressed only at unemployed workers, making it impossible to compare willingness to move by employment status.

${ }^{2}$ There exists a much larger literature on the relationship between unemployment and migration behavior. Most studies use US data and report a positive correlation between unemployment and migration probability. This positive relationship is shown to be stronger with individual's unemployment status than with regional unemployment rate. See Herzog Jr. et al. (1993) for a survey. 
Toharia and Jimeno (1995) estimate the probability of accepting a job offer which implies a reduced wage or residential/occupational changes. Using a cross-section data set they find that individual characteristics and unemployment benefits are among the most important determinants of the probability of accepting a job offer. In this paper, we examine migration willingness and unemployment duration using individual longitudinal data (rotating panel data), which alleviate the problems of unobserved heterogeneity and duration dependence which are a critical limitation in analyses of cross-section data.

We organize the paper as follows. First, we examine the determinants of the willingness to move for work among the Spanish unemployed. In this section, we highlight the relationship between unemployment duration and migration attitude after controlling for fixed individual effects using longitudinal data. We also examine how individuals' willingness to move for work changes as they remain unemployed for a longer period. Second, we examine the factors which affect unemployment duration with a special interest in the effect of workers' migration willingness. Considering that there might be unobserved factors which affect both migration willingness and unemployment duration, we estimate those two equations simultaneously to control for the endogeneity of migration willingness with respect to unemployment duration. The results confirm the importance of this consideration for males through a significant correlation coefficient and a substantial increase in the effect of migration willingness on unemployment duration when we control for endogeneity.

\section{DATA AND VARIABLES}

The data used for this study are taken from the Spanish Labour Force Survey (EPA) which is the main source of labour market information in Spain. This survey is undertaken each quarter on about 60,000 households (about 200,000 individuals). One-sixth of the sample are replaced by new households each quarter. Therefore a household, once chosen, is interviewed six times over an interval of about 15 months. However, the longitudinal nature of this survey could not be used until the Spanish Statistics Institute (INE) recently made available the individual identification code which identifies the same individuals in different quarters. Using this code we can now follow each individual through six consecutive quarters.

For the first part of the paper we use pooled cross-section data between the first quarter of 1992 and the final quarter of 1994 . For the second part of the paper where we analyse 
unemployment duration we construct individual longitudinal data from the rotating panal EPA from 1992:1 to 1995:2. The individuals interviewed for the first time in the first quarter of 1992 had their last interviews in the second quarter of 1993 and similarly, those who had had their first interview in the second quarter of 1992 had their last interview in the third quarter of 1993, and so on. The last cohort of our sample were interviewed from the fourth quarter of 1994 to the second quarter of 1995 . We restrict our sample to those whose unemployment duration at the time of the first interview is shorter than four months, mainly in order to reduce the potential unobserved heterogeneity bias that could arise from differences in the initial unemployment duration.

The dependent variable of the first part of our study is taken from the answer to the question: Would you accept a job offer which required a change of residence? (Henceforth, we call it willingness to move for work or migration attitude.) Possible answers are "yes", "no" and "don't know". In our sample $37 \%$ of responses were positive, $39 \%$ negative and $24 \%$ undecided. Over time we find that migration attitude is counter-cyclical: during recessions unemployed workers are more willing to move for work than during periods of expansion ${ }^{3}$.

The dependent variable for the second part of the study is duration of individual unemployment. The unemployment duration reported in the cross-section survey is censored at the date of interview, that is, the duration of on-going unemployment spells. Therefore, it is not suitable for the analysis of unemployment duration (see Kiefer (1988) for a detailed discussion on the problems of using censored data). The use of the longitudinal EPA helps us construct more adequate duration data, which include both complete and censored spells.

\section{WILLINGNESS TO MOVE FOR WORK}

\subsection{Theoretical Background}

At the outset, it is important to understand clearly our variable of analysis. The willingness to move for work that we analyse in this paper is not actual migration behavior but migration willingness based on a hypothetical question. In this respect it is different from

${ }^{3}$ According to the EPA, in 1987, when the unemployement rate was over $20 \%$, about $40 \%$ of the unemployed were willing to move for work. In 1991, with a $16 \%$ unemployment rate, the proportion who were willing to move was about $29 \%$. The proportion rose again to $33 \%$ in 1993 as the economy slipped back into recession. 
literature on actual migration but is similar to the work by Hughes and McCormick (1985) which analyses workers' migration intention. However, the migration intention they analyse is not identical to ours, as in our data the interviewees are asked about their willingness to move for work given a job offer from other regions while the interviewees in Hughes and McCormick (1985) do not have a job offer, so that they refer to migration intention to other regions as a job search strategy. Hence, the migration willingness analysed in our paper cannot be interpreted either as a direct representation of actual migration or as broader job search effort by workers as in Hughes and McCormick' ${ }^{4}$.

The willingness to accept a certain job offer will depend, according to the standard job search theory, on one's reservation wage and on one's expectations about future job offers one may receive, as well as search costs. Given an identical wage offer expectation, those with a lower reservation wage are more likely to accept a certain job offer. Individuals' reservation wages in turn depend on individual charateristics, family situation and regional economic situation. When the labour market is tight, those with greater family responsibility are more likely to accept a job offer than those with less responsibility. The composition of the household and each household member's situation, such as the presence of small children and the numbers of working members and the presence of unemployed members, are also likely to be relevant factors. Similarly, those with smaller alternative financial resources (such as savings or unemployment insurance) are more likely to accept a certain job offer. Also relevant are individual preferences for work, which are not observed but may be captured by some individual characteristics such as age, education and place of residence. The reservation wage

${ }^{4}$ Due to lack of data we cannot analyse the relationship between migration willingness and actual migration behavior. However, using data from the cross-sectional Spanish Labor Force Survey we can observe whether individuals have changed their place of residence in a one year period. Using this information we have compared individuals' migration experience during the past year with their willingness to move for work. This does show a positive relationship between past migration experience and migration willingness. According to the survey for the second quarter of 1993 about one percent of those with a positive migration willingness had migrated from other provinces while only $0.4 \%$ of others had done so. In any case, it should be kept in mind that the migration rate in Spain is in general extremely low: according to Antolin and Bover (1997), the rate is $0.3 \%$ among working age men. Although the difference in migration rate by the migration willingness is significant, the overall low migration rate makes one doubt the meaningfulness of the migration willingness used in this paper. In Section 3.1 we discuss in detail the meaning and interpretation of this variable. 
is also likely to be affected by the extent of human capital loss during unemployment spells. Those who face more rapid skill depreciation while unemployed will be more willing to accept a job offer. In this respect, occupation and educational level might be relevant variables. Current economic situation and expectations about future economic conditions are likely to affect one's willingness to move for work. For example, during a recession, when offers arrive less frequently, job offers are more likely to be accepted than during a period of expansion.

With respect to willingness to accept a job offer which requires a residential move, we may understand the reservation wage as being region specific. Workers have a reservation wage relevant for the local labour market and a possibly different reservation wage for each non-local labour market. In a simple framework, the reservation wage relevant to an outside labour market would be the reservation wage in the local market plus moving costs (pecuniary and non-pecuniary), where moving costs in a broad sense also include regional differences in job characteristics, lifestyle and quality of life. Under this framework, in addition to the factors which affect the reservation wage in the local market, any factor which affects moving costs are relevant for the analysis of willingness to move for work. For example, attachment to local culture and life-style and the degree of difference between regions could affect migration willingness. Furthermore, expected monetary moving cost, such as current housing type, living cost differences between regions, and regional differences in real wage, are also likely to be relevant.

\subsection{Some Determinants of Willingness to Move for Work}

In an empirical context, willingness to move for work can be specified as a latent variable which is determined by

$$
y_{1}^{*}=\beta_{1}^{\prime} x_{1}+\varepsilon_{1}
$$

where $\mathrm{y}_{1}{ }^{*}$, the expected net benefit of accepting a job which implies a residential move, is unobserved. What we observe is 
where in our case $\mathrm{y}_{1}=1$ if an individual is willing to move for work and $\mathrm{y}_{1}=0$ if not ${ }^{5}$.

$$
\begin{aligned}
y_{1} & =0 \text { if } y_{1}^{*} \leq 0, \quad \text { Assuming the extreme value } \\
& =1 \text { otherwise, distribution of the error term we }
\end{aligned}
$$

whose result is presented in Table 1 .

\section{(Table 1)}

Table 1 presents sample means, estimated odds ratios and asymptotic t-ratios. The male and female samples are estimated separately to capture possible differential effects of explanatory variables by sex. The odds ratios are computed by taking exponentials to the estimated coefficients and are interpreted as relative probability corresponding to a unit increase of each covariate. Below we discuss some important results.

The family relation shows significant effects, and in some cases different effects are observed by the employment status of the household head. Among males unmarried sons are about twice as willing to move for work as household heads. Among females, married women with a working husband are about four times less willing to move for work than female household heads or unmarried daughters. The comparison by age shows the expected decrease in willingness with age except for the youngest group (ages 16 to 19) who show lower willingness to move for work than older cohorts. This peculiarity of the youngest group suggests higher moving costs for some young people perhaps because they are staying in their parents' house. The probability of having a positive migration attitude decreases substantially

${ }^{5}$ The question of how to deal with the undecided (those who have responded with "Don't know") is a difficult one. One alternative is to include them in another category depending on belief. This treatment requires some supportive empirical tests. Our tests of pooling (using the method developed by Cramer and Ridder, 1991) reject strongly any pooling hypothesis. Another alternative is to treat them as a legitimate response or as missing observations. Treating them as a legitimate response causes problems in interpreting estimation results as well as added computational complication in estimating simultaneously migration willingness and unemployment duration, allowing a free correlation. Under these circumstances we opt to treat them as missing observations. Readers should be aware of the potential selection bias in our empirical results due to the exclusion of the undecided from our sample. The results of multinomial logit estimation treating the undecided as a legitimate alternative (reported in Appendix 1) indicate that the undecided are situated in between the two extremes with a tendency of being closer to those with negative attitude for the male sample. The results for the female sample do not show such an ordering as in the male sample. Also see the work by Rubin et al. (1995) for a discussion on how to handle with the undecided. 
for those aged over 40, reflecting higher moving costs (probably both economic and psychological costs).

The effect of education shows up at college level for males and at vocational school level for females. University graduates are about six to nine times more willing to move than those with a lower level of education. This might be due to a greater loss in earnings and human capital among the better educated and the differences in preferences for work by education.

Surprisingly, unemployment benefits do not seem to affect migration willingness. Benefit receivers are slightly (but not significant) less willing to move for work than others. According to work experience, the willingness to move for work is about $60-80 \%$ lower among first time job seekers than among workers with experience, which might reflect higher moving costs among the former (many of whom probably live in their parents' house) due to the lack of financial resources necessary to establish themselves in other regions.

With respect to household composition variables, increases in unemployed workers in the household conditional on the household size appear to increase the willingness to move for work among males. However, the number of children and the household size do not show any effects for either males or females. One of the possibly important factors that we do not observe is housing type. Previous studies (see, for example, Hughes and McCormick, 1985) have shown a significantly smaller migration intention among owner-occupiers than among tenants. We expect this difference to hold for Spain since rented housing is relatively expensive and fiscally less advantageous than owner occupied housing.

Some local economic variables appear to affect significantly workers' migration willingness. Contrary to a popular hypothesis, the willingness of unemployed workers in regions with a higher unemployment rate to move for work is no different from that of those in regions with lower unemployment rates $^{6}$. Vacancy rate decreases migration willingness among males as expected. On the other hand, local real wages increase willingness to move while regional house prices decrease it, again contradicting the hypothesis that those living in

${ }^{6}$ Previous studies have found conflicting results. They might be summarized by saying that the local unemployment rate tends to increase outmigration in the U.S. while its effect in the European countries is in general not significant, with a tendency to obtain a negative effect (see the survey by Herzog Jr. et al., 1993). For Spain, Bentolila and Dolado (1991) find a significant negative effect of local unemployment rate in net migrations. 
regions of lower house prices face higher moving $\operatorname{costs}^{7}$. This may be due to some omitted factors which are correlated with house prices, such as quality of life.

\subsection{Effects of Unemployment Duration on Willingness to Move for Work}

In the presence of a high proportion of long-term unemployed, as in Spain, one of the most interesting factors one can consider in examining migration willingness is the duration of unemployment. The relationship between willingness to move for work and unemployment duration is ambiguous. On the one hand, the longer-term unemployed are more likely to have exhausted unemployment insurance as well as other income sources, which is likely to lower their reservation wage, and therefore increase their willingness to accept a job offer. On the other hand, there is likely to exist unobserved heterogeneity which affects workers' migration willingness and their unemployment duration in opposite directions. For example, non-labour income or moving costs (which are not observed in our data) will increase a worker's reservation wage, hence increasing unemployment duration while decreasing migration willingness. Furthermore, as the duration of unemployment becomes longer, expected lifetime earnings from future work become smaller due to a reducing future working period (assuming constant retirement age), therefore lowering willingness to accept job offers as unemployment gets longer. Without controlling for these conflicting factors it is difficult to establish the correct relationship between migration willingness and unemployment duration.

Previous empirical studies have shown conflicting results on the effect of unemployment duration on the probability of migration. Goss and Schoening (1984) show a positive effect of unemployment status, but a negative effect of unemployment duration on actual migration in the US. On the other hand, Hughes and McCormick (1985) show a positive effect of unemployment duration on migration intention in the UK.

We start with a simple comparison of the willingness to move for work among the currently unemployed by their on-going unemployment duration using a pooled cross-section dataset (EPA 1992/I-1994/IV). The results shown in Table 2 indicate no systematic variation in migration willingness by unemployment duration, except that the proportion of positive

${ }^{7}$ It should be noted that there is a high correlation (0.72) between regional house prices and regional real wages, which might affect estimation results. When house price is dropped from the estimation, the effect of local wage rate turns out to be significantly negative, probably because it captures practically all the effect of house price. 
migration attitude is somewhat lower among female workers with on-going unemployment spells longer than 36 months than among those with a shorter duration. This leads us to suspect the existence of uncontrolled heterogeneity among unemployed workers which affects both workers' attitude and their probability of transition from unemployment. For example, the group of the long-term unemployed is likely to include a higher proportion of workers with low migration willingness than the short-term unemployed.

(Table 2)

\subsubsection{Control of Unobserved Fixed Individual Effect}

Now, using a longitudinal dataset, we control for unobserved fixed individual effects and examine the effect of unemployment duration on willingness to move for work. We examine how individuals' migration willingness changes as their unemployment lasts longer. In the Spanish Labour Force Survey individuals are interviewed six times (every three months over a period of one and a half years), allowing us to examine unemployed workers' migration willingness as their unemployment duration lengthens. For example, for those who are unemployed for two consecutive quarters, we can examine the variation of migration willingness as their unemployment duration increases by about three months. For the group of people who are unemployed over the entire interview period (six quarters), we can examine how attitude changes as duration of unemployment increases by about 15 months (time elapsed between the first and the sixth interview) for the same group of unemployed workers.

Table 3 shows how migration willingness changes as duration of unemployment increases. All individuals in the sample were unemployed up to 3 months at the time of their first interview. We divide the sample into subgroups according to the period when individuals become employed, including a group of workers who stay unemployed over the entire time period of six interviews. We exclude those who end their unemployment spells by leaving the labour force because we suspect that they are different from those who end their unemployment spells by finding a job ${ }^{8}$.

(Table 3)

One clear conclusion which can be drawn from the results in Table 3 is that migration

${ }^{8}$ Ahn and Ugidos (1995) find the importance of distinguishing between exits to nonparticipation and those to employment in a study of unemployment duration. 
willingness does not change with unemployment duration even after controlling for unobserved fixed individual effects. For example, among those who are unemployed during all 6 quarters interviewed (last column of Table 3 ) the proportion of workers willing to move remains virtually the same in all quarters. Similarly, among those who end their unemployment spells during one of the quarters interviewed, the proportion of workers with a positive migration attitude does not vary much with unemployment duration. That is, unemployed workers do not change their migration attitude even when their unemployment spells get longer and longer. We can think of three reasons for this finding.

First, one might think that the responses to the hypothetical question as posed in the Survey might be completely random ${ }^{9}$. This case can be considered as people drawing a ball each quarter from a jar which contains approximately 50 percent (approximate proportion of the positive answers in our data) of balls with a positive response and 50 percent of balls with a negative response. In this case individuals' response would not depend on the duration of unemployment or on their past responses. Under this hypothesis, the probability of showing a positive (negative) response in any quarter would be about 50\% (50\%) regardless of the response revealed in the previous interviews. The second hypothesis is that the lack of variation over unemployment duration might be because individuals' attitude is very rigid. Maybe attitude just does not change for whatever reason. People might maintain the same attitude regardless of their unemployment duration. In this case, the conditional probability of showing a positive or negative attitude at period $t+1$ would be one or zero depending completely on the attitude shown in period t. Both hypotheses are clearly rejected by the transition matrix shown in Table 4.

(Table 4)

It appears that there is strong persistence over time in attitudes. Those who show a certain attitude in one period are very likely to show the same attitude in subsequent periods. However, it also appears that attitude is not totally fixed. Although persistence seems to be strong, there are also a substantial number of people who change their attitudes. In our sample

${ }^{9}$ It should be kept in mind that in order to collect information on every household member the interviewer asks questions about all household members of those adults who happen to be at home at the time of interview. This means that the information about willingness to move for some individuals in the survey may be based on other household members' opinion. 
about a nine percent of the unemployed workers changed their attitude over a period of 3 months. However, the transitions from positive to negative are almost exactly offset by the transitions from negative to positive (268 vs. 262), therefore maintaining constant overall distribution of attitude over time as shown in Table 3. To examine these transitions we consider the factors which could affect workers' attitude over unemployment duration. The question addressed in the following section is who are more likely to change their attitude over time and what makes them change.

\subsubsection{Dynamics of Willingness to Move for Work}

One can think of many factors that can contribute to changing individuals' attitude over time. As discussed earlier, with lengthening unemployment duration people might run out of economic resources, which makes them more willing to move for work. On the other hand, as unemployment duration gets longer, people somehow find ways to live without a formal job, for example if the probability of operating in the underground economy increases with unemployment duration, job offers from other regions become less attractive (Ahn and De la Rica, 1997), and if they are likely to classify themselves as unemployed in the survey, this could lead to an increase in the proportion of negative attitude as the duration of unemployment increases. It is also possible that preferences for work or leisure change as one spends more time unemployed. Unfortunately, in our dataset we do not have much information about changes in individuals' economic situation or in their preferences.

One variable that is available for our analysis is individual status regarding unemployment benefits each quarter. We observe whether or not unemployed workers receive unemployment benefit at the time of each interview. Therefore, between two consecutive quarters we can compare three types of people: those who continue to receive unemployment benefit, those who exhaust it, and finally those who do not receive it in either of the two quarters ${ }^{10}$. The exhaustion of unemployment benefit is likely to lead to a sudden drop (although known beforehand) in financial resources, and is likely to increase individuals' willingness to

${ }^{10}$ There are some unemployed workers (about 10\%) who start their unemployment spells without unemployment benefit but receive it in later (mostly in the second) quarter. We treat them as if they received benefit from the beginning since this is mostly due to delayed payment of benefit. 
move for work ${ }^{11}$. Comparing the attitude of those who exhaust their unemployment benefit at some time between two periods with those who continue receiving it, we can examine the importance of economic means for workers' willingness to move for work. Furthermore, we examine whether changes in the number of workers or unemployed in the household affect the willingness to move for work. We expect an increasing (decreasing) transition probability from negative to positive as the number of unemployed (workers) increases.

In this section we examine the factors which could change individuals' migration willingness over an interval of three months. In our sample $39.6 \%$ maintain a positive attitude, $51.7 \%$ maintain a negative attitude, $4.3 \%$ change their attitude from negative to positive, and $4.4 \%$ change from positive to negative. As explanatory variables, besides the time-varying variable representing the receipt of unemployment benefit in each quarter and changes in the number of workers and unemployed in the household, we include some time-invariant demographic variables which could affect the transition tendency of individuals' attitudes. Among the few previous studies, Goss and Paul (1990) and Antolin and Bover (1997) find a negative effect of unemployment benefits on actual migration among U.S. and Spanish displaced workers, respectively ${ }^{12}$.

\section{(Table 5)}

Table 5 shows the multinomial logit estimation results of the transition probability of migration attitude with four alternatives: positive-positive, positive-negative, negative-positive and negative-negative. The probability of changing attitude from negative to positive (the first and the third columns of Table 5), relative to maintaining negative attitude, is $30-60 \%$ higher among those who have exhausted their unemployment benefit than among those who continue to receive it. This is the first evidence in our study which indicates that the economic situation facing unemployed workers is important in determining their willingness to move for work. Another interesting result is that increases in unemployed workers in the household increase the transition probability from negative to positive, whereas this effect is absent among the female sample, suggesting that male workers are more sensitive to changes in other household

${ }^{11}$ Many studies have found a significantly higher job-finding probability after the exhaustion of unemployment benefit. See, for example, Ahn and Ugidos (1995) and Meyer (1990), or Atkinson and Micklewright (1991) for a survey.

${ }^{12}$ In the case of Antolin and Bover (1997), the variable considered is not the receipt of unemployment benefits but registration at a public employment office for Spain. 
members' labour market situation than female workers.

The demographic variables confirm more or less the results obtained in the previous section (Table 1). Unmarried children (especially sons) are more likely to change their attitude to a positive one while married women are much less likely to do so. The transition probability from negative to positive decreases substantially with age, especally after 40. As mentioned previously, one of the factors that affect willingness to move for work is the loss of earnings and human capital during unemployment spells. This loss is likely to increase as unemployment duration gets longer, and more so among the educated. Hence, we would expect the probability of changing migration attitude from negative to positive to be greater among the better educated. The results show that education has different effects for males and females; while it has no significant effect for males, females with university education show a much higher probability of changing to positive attitude. This might be due to the fact that university education represents individuals' career aspirations (which must be positively correlated with willingness to move for work) to a greater extent among women than among men.

The probability of changing attitude from positive to negative (second and fourth columns of Table 5) is lower among the unmarried and the better educated, but higher when unemployment benefits are exhausted, which is not readily explicable.

\section{EFFECT OF MIGRATION ATTITUDE ON UNEMPLOYMENT DURATION}

Given the result from the previous section that an individual's attitude is very much fixed with respect to his/her unemployment duration, it is interesting to examine how individuals' attitudes affect their unemployment duration. For an empirical analysis we take advantage of the longitudinal nature of the Survey to measure the duration of unemployment until individuals find a job. All individuals in our working sample were unemployed for less than 4 months at the time of their first interview. To determine duration of unemployment we use information on whether these individuals are employed or remain unemployed in each of the subsequent five interviews.

\subsection{The Problem of Attrition}

Before we carry on further, we need to concern ourselves with a common problem in the analyses of longitudinal data: the problem of attrition. It is common for a part of the initial 
sample to be lost over time. In EPA, if a household moves, or if simply nobody is at home or cooperates when the interviewers visit the house, no information is obtained for this household. If the missing population are not randomly distributed with respect to the variables which concern us, estimation results are likely to be biased. This consideration is particularly important in our study because our main variable is individuals' migration attitude. Those who have a positive migration attitude are more likely to migrate (footnote 4), more likely to search more intensively and more likely to have found a job ${ }^{13}$, and therefore more likely to be lost from the survey, than those with a negative attitude. In this case, the effect of attitude on jobfinding probability will be underestimated.

\section{(Table 6)}

In our sample, as shown in Table 6, about 30 percent of the initial sample are not observed in one of the five subsequent quarters, representing an attrition rate of about $7 \%$ per quarter. The attrition rate is also slightly higher among females, heads of household, those aged 25-39 and those with university education. The most interesting variable to see is migration attitude. As mentioned before, it is natural to expect a higher attrition rate among those with a positive migration attitude. Indeed, as shown in Table 7, those with a positive attitude seem to become lost more frequently than those with negative attitude. However, the difference is only marginally significant. This lack of difference in spite of a large sample size may be due to the extremely low migration rate in Spain in recent years (Antolin and Bover, 1997). Given this result we ignore the potential bias due to attrition in our subsequent analysis $^{14}$.

(Table 7)

\subsection{Unemployment Duration: Empirical Literature}

There exists a huge literature, both theoretical and empirical, on the duration of

${ }^{13}$ Given a much lower migration rate compared to the attrition rate in the Survey, attrition is mainly due to the absence of all household members from home.

${ }^{14}$ Van den Berg et al. (1994) estimate the correlation between unobservable variables in the unemployment duration and attrition using the Dutch panel data where attrition rate is about 50 percent over a period of two and a half years. Their results show that the correlation is not significantly different from zero. We also believe that our empirical results would not change much as a result of this potential attrition bias. However, readers should be aware of this potential bias. 
unemployment. Most studies are mainly concerned with the effects of unemployment benefits on duration of unemployment (see Devine and Kiefer, 1991 and Atkinson and Micklewright, 1991 for a survey). In this section, besides the variables of conventional interest such as unemployment benefit and family characteristics, we highlight the effect of workers' migration willingness on their unemployment duration (jobfinding probability).

How does migration attitude affect unemployment duration? All things being equal, workers with a positive attitude are likely to have shorter unemployment spells because their job search area may be broader than those with a negative attitude. However, in a country like Spain, where migrations are observed to be extremely rare in recent years, it is difficult to associate migration willingness with job-search area. We think it is more suitable to associate it with individuals' job-search intensity or preferences for work. In this context, those with a positive attitude are likely to look for a job more intensively and are more likely to accept a certain job offer than those with negative attitude, and therefore have shorter unemployment spells on average. On the other hand, one's migration willingness may be reflecting one's past job search experience or future perspectives. Those who have had a bad experience (such as low probability of receiving offers) are more likely to have a positive willingness to move for work. If negative past experience (or future expectation) is due to some undesirable worker characteristics, migration willingness could have a negative correlation with jobfinding probability.

Within our knowledge, there are no studies on the effect of migration willingness on unemployment duration. Some studies which analyse the effect of actual migration on reemployment probability suggest conflicting effects with a mild tendency towards positive, but inconclusive, effects (see the survey by Herzog Jr. et al. (1993)).

\subsection{Empirical Specification}

We use an ordered-probit model to analyse unemployment duration. To alleviate any bias that could arise from heterogeneous initial conditions we restrict our sample to those whose on-going unemployment duration at the time of the first interview is less than 4 months ${ }^{15}$. Unemployment duration is constructed as an ordered variable. It is ordered by the

${ }^{15}$ Therefore, the maximum duration of unemployment observed in our working sample is 18 months: 3 months in unemployment at the time of first interview plus 15 months of additional unemployment if interviewees stay unemployed until the last 
number of quarters elapsed before individuals find a job, including those who never find a job during the entire interview periods as the highest order. The ordered-probit model can be described in the same way as the binary probit model. Ignoring the individual index, we begin with,

$$
y_{2}^{*}=\beta_{2}^{\prime} x_{2}+\varepsilon_{2}
$$

where $\mathrm{y}_{2}{ }^{*}$ is a latent variable and denotes unobserved exact unemployment duration. What we observe is

$$
\begin{aligned}
& \qquad \begin{aligned}
y_{2} & =1 \text { if } y_{2}{ }^{*} \leq \mu_{1}, \quad \text { where the value of } y_{2} \text { is the } \\
& =2 \text { if } \mu_{1}<y_{2}{ }^{*} \leq \mu_{2}, \quad \text { number of quarters elapsed }
\end{aligned} \\
& \text { before the individual finds a job, }=3 \text { if } \mu_{2}<y_{2}{ }^{*} \leq \mu_{3}, \\
& \text { where its maximum value }(6) \begin{array}{r}
\ldots \\
=
\end{array}
\end{aligned}
$$

survey (6 quarters), and $\mu$ 's are unknown threshold parameters to be estimated with the $\beta_{2}$ 's. The estimated $\beta_{2}{ }^{\prime}$ s are interpreted so as to increase (if positive) or decrease (if negative) the probability of having longer unemployment spells.

One statistical problem with the above model is that migration attitude, an explanatory variable of our main interest, is likely to be endogenous with respect to unemployment duration. This is true if there are some common unobserved determinants of both attitude and duration. For example, non-labour family income, which is not observed in our data, affects both attitude toward migration and duration of unemployment through individuals' reservation wage. In this case, the effect of migration attitude on unemployment duration is likely to be biased in the estimation (see Griliches 1977). To correct this bias we estimate two equations, one for attitude and the other for unemployment duration simultaneously, allowing for free correlation between the error terms in the two equations.

We specify the empirical model by assuming a bivariate normal distribution between the error terms in equations (1) and (2). Then we can write the probabilities of observing results of the estimation using the sample with a longer initial duration were virtually the same as the ones reported in the paper. 
individuals with a certain migration attitude $\mathrm{y}_{1}$ and a certain unemployment duration $\mathrm{y}_{2}$ as follows.

$$
\begin{aligned}
\operatorname{Pr}\left(y_{1}=0, y_{2}=1\right)=F\left(-\beta_{1}^{\prime} x_{1}, \mu_{1}-\beta_{2}^{\prime} x_{2} ; \rho\right) ; & \text { where } \mathrm{F} \text { is the bivariate normal } \\
\operatorname{Pr}\left(y_{1}=1, y_{2}=1\right)=F\left(\beta_{1}^{\prime} x_{1}, \mu_{1}-\beta_{2}^{\prime} x_{2} ;-\rho\right) ; & \text { probability } \\
\operatorname{Pr}\left(y_{1}=0, y_{2}=2\right)=F\left(-\beta_{1}^{\prime} x_{1}, \mu_{2}-\beta_{2}^{\prime} x_{2} ; \rho\right)-F\left(-\beta_{1}^{\prime} x_{1}, \mu_{1}-\beta_{2}^{\prime} x_{2} ; \rho\right) ; & \begin{array}{l}
\text { distribution } \\
\text { function }
\end{array} \\
\operatorname{Pr}\left(y_{1}=1, y_{2}=6\right)=F\left(\beta_{1}^{\prime} x_{1},-\mu_{6}+\beta_{2}^{\prime} x_{2} ; \rho\right), & \text { and } \rho \text { the correlation coefficient. }
\end{aligned}
$$

Obviously, in estimating the

model identification issue arises. Formally, the bivariate probit model is identified due to the non-linear functional form of its normal probability distribution. However, it is known that identification based only on this is very tenuous, and therefore requires exclusion restrictions (Keane (1992)). Moving cost is an adequate identifying variable since it affects workers' migration willingness but not unemployment duration. Regional average house prices and real wages are used to proxy moving cost in our analysis. We also include household situation variables (such as presence of children and number of workers and unemployed in the household) as additional identification variables since they are supposed to affect the decision to participate in the labour market and possibly moving costs (therefore willingness to move for work) but not unemployment duration.

\subsection{Results}

The results of the simultaneous estimation of unemployment duration and migration willingness are shown in Table 8. Due to the similarity of the results of migration willingness equation to those in Table 1, we only report the results of the unemployment duration equation.

(Table 8)

First, it is worth comparing the effect of migration attitude with and without (Table 2 in Appendix) controlling for endogeneity. The estimated coefficient of migration attitude for the male sample is substantially higher when we control for endogeneity than when we do not. Furthermore, there is a significant correlation between the two equations. These results suggest that it is important to control for endogeneity in the male sample. On the other hand, there seems to be no correlation for the female sample. Below we discuss our empirical results.

Male workers who have a positive attitude toward migration find jobs considerably faster than other males, while the effect is not significant among female workers. This 
difference by gender may come about because the labour market is more demand driven for females than for males, therefore migration attitude matters less for female workers in determining their unemployment duration than for male workers. This interpretation is also in accordance with a much higher unemployment rate among females than males in Spain. However, further investigation is needed to find more convincing interpretations.

Other variables confirm more or less the results found in other studies. In general, sons, daughters and married women are much slower at finding jobs than the head of household. However, the pace of jobfinding among non-heads varies by the employment status of the household head. Those (especially among males) in a household in which the head is unemployed appear to find jobs faster than otherwise. This is consistent with a theoretical prediction that unemployment of the household head would lower acceptable wage levels for other household members. With respect to age, jobfinding pace shows a decreasing tendency among the male sample but no significant variation among the female sample. On the other hand, education shows no effects.

To control for demand factors in the labour market, we include the occupation held prior to unemployment, including those who have never worked in the reference category. The results show that occupation significantly affects individuals' jobfinding probabilities. First, for both males and females, first-time job seekers are having much greater difficulties in finding jobs than others. Among those with work experience, agricultural workers, male managers and female professionals end unemployment spells earlier than others. The shorter spells among agricultural workers may reflect the seasonal nature of jobs in this sector while the shorter spells among managers and professionals reflect a greater labour demand for these occupations.

As in previous studies, unemployment benefits delay exits from unemployment. The business cycle effect appears to be important for males but not for females. For males, spells starting in 1994, when the economy entered recovery, are shorter than those which started earlier. Local labour market conditions also show the expected effects although in some cases they are insignificant: the higher the local unemployment rate the longer the spells, and the greater the vacancy rate the shorter the spells.

\section{CONCLUSIONS}


In this paper we have examined Spanish unemployed workers' willingness to move for work and its relationship with their unemployment duration. We use a question in the Spanish Labour Force Survey: "Would you accept a job offer which implied a change of residence?" First, we have found that those in their teens, those over 50 years old, and married women are least willing to move for work, while unmarried young adults are most willing. Migration willingness increases significantly with education level. The increase is highest among university educated females, perhaps due to a higher correlation between education and career aspirations among women. Surprisingly, unemployment benefit does not seem to affect migration willingness.

Second, migration willingness does not change with unemployment duration even after controlling for unobserved fixed individual effects, leading us to consider the possibility that Spanish workers' migration willingness is completely random or totally fixed. Both hypotheses are strongly rejected according to the analysis of the conditional probability of migration willingness over unemployment duration. It is shown that there are substantial fixed components in Spanish unemployed workers' migration willingness, but there are also a considerable number of workers who change their attitude. Among the major factors that make people change their migration attitude from negative to positive are the exhaustion of unemployment benefit and the incidence of unemployment among other household members.

Another important finding is that male unemployed workers with a positive attitude find jobs considerably faster than other males, while the effect is not significant among the female sample. Perhaps the labour market is more demand driven for females than for males, so that migration attitude matters less for female workers in determining their unemployment duration.

In conclusion, our research suggests that the majority of unemployed workers are unwilling to move for work. This negative attitude does not change even when unemployment duration gets longer. This might be attributed to the traditional Spanish lifestyle and culture. However, the significant improvement of migration attitude after exhaustion of unemployment benefits suggests that economic incentives could play an important role in increasing worker mobility. In this respect an improvement of the rented housing market is also likely to be a help. Further studies which examine the roles played by economic and labour market situations in a family context and housing type among others are likely to be valuable. 


\section{REFERENCES}

Ahn N. and S. de la Rica (1997) "The underground economy in Spain: an alternative to unemployment?" Applied Economics, 29: 733-743.

Ahn N. and A. Ugidos (1995) "Duration of unemployment in Spain: relative effects of unemployment benefit and family characteristics", Oxford Bulletin of Economics and Statistics, 57(2): 249-264.

Antolin P. and O. Bover (1997) "Regional migration in Spain: the effect of personal characteristics and of unemployment, wage and house price differentials using pooled cross-sections" Oxford Bulletin of Economics and Statistics, 59(2): 215-235.

Atkinson A.B. and J. Micklewright (1991) "Unemployment compensation and labour market transitions: A Critical Review." Journal of Economic Literature, 29: 1679-1727.

Bentolila S. (1997) "Sticky labor in Spanish regions", European Economic Review 41: 591598.

Bentolila S. and O. Blanchard (1990) "Spanish Unemployment." Economic Policy, 10.

Bentolila S. and J. Dolado (1991) "Mismatch and Internal migration in Spain, 1962-86." in Mismatch and Labour Mobility, (ed.) F. Padoa-Schioppa, Cambridge University Press.

Cramer J.S. and G. Ridder (1991) "Pooling states in the multinomial logit model", Journal of Econometrics, 47: 267-272.

Devine T.J. and N.M. Kiefer (1991) Empirical Labor Economics: The Search Approach. Oxford University Press: New York.

Faini R., G. Galli, P. Gennari and F. Rossi (1997) "An empirical puzzle: Falling migration and growing unemployment differentials among Italian regions", European Economic Review 41: 571-579.

Goss E. and N.C. Schoening (1984) "Search time, unemployment, and the migration decision", Journal of Human Resourses, 19: 570-579.

Griliches Z. (1977) "Estimating the returns to schooling: some econometric problems." Econometrica 45, pp. 1-22.

Herzog Jr. H.W., A.M. Schlottmann and T.P. Boehm (1993) "Migration as Spatial Jobsearch: A Survey of Empirical Findings", Regional Studies, 27(4): 327-340.

Hughes G.A. and B. McCormick (1985) "Migration Intentions in the U.K.: Which Households Want to Migrate and Which Succeed?", The Economic Journal, 95: 113-123.

Jimeno J.F. and S. Bentolila (1995) "Regional Unemployment Persistence: Spain, 1976-1994." 
Documento de Trabajo 95-09, FEDEA.

Keane M.P. (1992) "A Note on Identification in the Multinomial Probit Model", Journal of Business \& Economic Statistics, 10(2): 193-200.

Kiefer N.M. (1988) "Economic duration data and hazard functions", Journal of Economic Literature, 26: 649-679.

Meyer B.D. (1990) "Unemployment Insurance and Unemployment Spells", Econometrica, 58: 757-783.

Rubin D.B., H.S. Stern and V. Vehovar (1995) "Handling"Don't Know" Survey Responses: The Case of the Slovenian Plebiscite", Journal of the American Statistical Association, 90: 822-828.

Toharia L. and J.F. Jimeno (1995) "Los hechos básicos del paro" in El paro en España: ¿Tiene solución? Center for Economic Policy Research.

Van den Berg G.J., M. Lindeboom and G. Ridder (1994) "Attrition in longitudinal panel data and the empirical analysis of dynamic labour market behaviour." Journal of Applied Econometrics, 9: 421-435. 
Table 1: Willing to Move for Work?

Result of Logistic Regression (Data: EPA 1992/I-1994/IV)

(Dependent Variable: $\mathrm{Yes}=1$ and $\mathrm{No}=0$; t-statistics in parenthesis)

\begin{tabular}{|c|c|c|c|c|}
\hline \multirow[b]{2}{*}{ Variables } & \multicolumn{2}{|c|}{ Male $(\mathrm{N}=2327)$} & \multicolumn{2}{|c|}{ Female $(\mathrm{N}=1258)$} \\
\hline & Mean & Odds ratio & Mean & Odds ratio \\
\hline \multicolumn{5}{|c|}{ Relation to Head of Household } \\
\hline Head & 0.43 & reference & 0.06 & reference \\
\hline Spouse, head work & --- & --- & 0.24 & $0.25(3.62)$ \\
\hline Spouse, head unem & --- & --- & 0.07 & $0.70(0.79)$ \\
\hline Spouse, head inac & --- & --- & 0.03 & $0.84(0.29)$ \\
\hline Child, head work & 0.22 & $2.08(3.24)$ & 0.33 & $1.33(0.66)$ \\
\hline Child, head unem & 0.06 & $1.81(2.00)$ & 0.07 & $1.12(0.23)$ \\
\hline Child, head inac & 0.23 & $2.32(4.45)$ & 0.18 & $1.39(0.79)$ \\
\hline Others & 0.01 & $0.96(0.17)$ & 0.01 & $1.06(0.11)$ \\
\hline \multicolumn{5}{|l|}{$\underline{\text { Age }}$} \\
\hline $16-19$ & 0.11 & $0.44(3.57)$ & 0.18 & $0.49(2.23)$ \\
\hline $20-24$ & 0.22 & $1.23(1.12)$ & 0.29 & $1.14(0.48)$ \\
\hline $25-29$ & 0.17 & $1.46(2.23)$ & 0.17 & $1.08(0.30)$ \\
\hline $30-39$ & 0.23 & reference & 0.21 & reference \\
\hline $40-49$ & 0.16 & $0.68(2.36)$ & 0.12 & $0.52(1.93)$ \\
\hline $50+$ & 0.11 & $0.32(5.20)$ & 0.03 & $0.13(2.48)$ \\
\hline \multicolumn{5}{|l|}{ Education } \\
\hline None & 0.13 & $0.96(0.26)$ & 0.07 & $0.79(0.62)$ \\
\hline Primary & 0.38 & reference & 0.25 & reference \\
\hline Secondary & 0.40 & $1.17(1.33)$ & 0.48 & $1.22(1.04)$ \\
\hline Vocational & 0.05 & $1.28(1.01)$ & 0.09 & $1.95(2.40)$ \\
\hline Jr. College & 0.01 & $1.61(1.07)$ & 0.06 & $4.98(4.52)$ \\
\hline University & 0.03 & $5.78(4.18)$ & 0.06 & $9.18(5.83)$ \\
\hline Ever Worked & 0.91 & $1.87(3.11)$ & 0.82 & $1.64(2.42)$ \\
\hline \multicolumn{5}{|c|}{ Relation to Public Employment Office (INEM) } \\
\hline Receiving subsidy & 0.39 & $0.90(0.55)$ & 0.25 & $0.96(0.14)$ \\
\hline Only registered & 0.53 & $1.12(0.64)$ & 0.64 & $1.04(0.16)$ \\
\hline Not registered & 0.08 & reference & 0.11 & reference \\
\hline \multicolumn{5}{|c|}{ Household Composition } \\
\hline Household Size & 4.50 & $1.04(0.92)$ & 4.40 & $0.95(0.72)$ \\
\hline \# workers & 0.77 & $0.95(0.73)$ & 1.06 & $1.13(1.08)$ \\
\hline \# unemployed & 1.57 & $1.37(4.00)$ & 1.47 & $1.05(0.41)$ \\
\hline Children $0-6$ years & 0.17 & $1.07(0.52)$ & 0.15 & $0.80(0.88)$ \\
\hline Children 7-15 & 0.38 & $0.95(0.64)$ & 0.34 & $0.81(1.11)$ \\
\hline
\end{tabular}




\begin{tabular}{|c|c|c|c|c|}
\hline \multicolumn{5}{|l|}{ Year (re: 1992) } \\
\hline 1993 & 0.37 & $1.05(0.43)$ & 0.35 & $1.11(0.58)$ \\
\hline 1994 & 0.32 & $1.14(1.06)$ & 0.35 & $1.10(0.52)$ \\
\hline \multicolumn{5}{|c|}{ Local Economy Condition } \\
\hline Log unemp. rate & 2.96 & $1.06(0.30)$ & 2.86 & $1.23(0.73)$ \\
\hline Log vacancy rate & 3.59 & $0.51(2.94)$ & 3.54 & $0.80(0.72)$ \\
\hline Log real wage & 6.73 & $1.49(0.49)$ & 6.74 & $7.45(1.84)$ \\
\hline Log house price & 6.58 & $0.33(2.70)$ & 6.61 & $0.17(3.10)$ \\
\hline Model Chi-square & & 604.87 & & 382.49 \\
\hline
\end{tabular}

Unsigned asymptotic t-statistics in parentheses. Also included (but not reported) are the region variables. 
Table 2: Willing to Move for Work?

Percentage of Positive Answers

From Cross-Section Data (EPA 1992/I-1994/IV)

\begin{tabular}{|c|c|c|c|c|c|}
\hline & \multirow{2}{*}{$\stackrel{\text { All }}{\%}_{\%}$} & \multicolumn{2}{|c|}{ Male } & \multicolumn{2}{|c|}{ Female } \\
\hline & & $\%$ & $\mathrm{~N}$ & $\%$ & $\mathrm{~N}$ \\
\hline \multicolumn{6}{|c|}{ By Current Unemployment Duration (months) } \\
\hline $0-6$ & 46.8 & 55.7 & 5190 & 34.6 & 3765 \\
\hline $7-12$ & 46.6 & 55.8 & 2092 & 36.4 & 1876 \\
\hline $13-18$ & 46.6 & 57.1 & 1141 & 36.1 & 1151 \\
\hline $19-24$ & 44.6 & 57.8 & 1794 & 34.5 & 2319 \\
\hline $25-36$ & 45.2 & 59.2 & 709 & 36.1 & 1086 \\
\hline 37 or more & 41.7 & 59.2 & 1179 & 32.5 & 2249 \\
\hline
\end{tabular}


Table 3: Willing to Move for Work?

Percentage of Positive Answers

From Longitudinal Data (EPA 1993/I-1994/IV)

\begin{tabular}{lcccccc}
\hline & \multicolumn{5}{c}{ Number of Consecutive Quarters Unemployed } \\
\cline { 2 - 5 } $\begin{array}{l}\text { Response in ith } \\
\text { Interview }\end{array}$ & 1 & 2 & 3 & 4 & 5 & $6+$ \\
\hline 1st & 51.6 & 52.0 & 53.5 & 47.9 & 45.6 & 42.7 \\
2nd & & 53.6 & 51.7 & 43.8 & 46.5 & 40.1 \\
3rd & & & 54.3 & 43.8 & 43.0 & 40.8 \\
4th & & & & 44.4 & 50.0 & 40.6 \\
5th & & & & & 51.8 & 39.5 \\
6th & & & & & & 40.4 \\
Average & 51.6 & 52.8 & 53.2 & 45.0 & 47.4 & 40.7 \\
& & & & & & \\
Observations & 1104 & 542 & 381 & 169 & 114 & 759 \\
\hline
\end{tabular}


Table 4: Transition Matrix of Willingness to Move for Work Over Three Months Interval

\begin{tabular}{lcr}
\hline & \multicolumn{2}{c}{ Attitude in i+1th Interview } \\
Attitude in ith Interview & Positive & Negative \\
\hline Positive (2661) & 2393 & 268 \\
Negative (3649) & 262 & 3387 \\
\hline
\end{tabular}

Source: Longitudinal EPA 1992/I - 1994/IV. 
Table 5: Logit Regression of Transitions in Willingness to Move for Work Estimated Odds Ratio

\begin{tabular}{|c|c|c|c|c|}
\hline & \multicolumn{2}{|c|}{$\underline{\text { Male }}$} & \multicolumn{2}{|c|}{$\underline{\text { Female }}$} \\
\hline & $\begin{array}{r}\mathrm{P}(\text { no-yes }) / \\
\mathrm{P}(\text { no-no })\end{array}$ & $\begin{array}{l}\mathrm{P}(\text { yes-no }) / \\
\mathrm{P}(\text { yes-yes })\end{array}$ & $\begin{array}{r}\mathrm{P}(\text { no-yes }) / \\
\mathrm{P}(\text { no-no })\end{array}$ & $\begin{array}{l}\mathrm{P}(\text { yes-no }) / \\
\mathrm{P}(\text { yes-yes })\end{array}$ \\
\hline Head & reference & reference & reference & reference \\
\hline Spouse & --- & -- & $0.18(3.41)$ & $0.32(1.97)$ \\
\hline Son/Daughter & $2.48(3.44)$ & $0.72(1.26)$ & $0.68(0.68)$ & $0.08(4.09)$ \\
\hline Other & $3.03(2.57)$ & $1.27(0.53)$ & $1.29(0.30)$ & $0.18(2.03)$ \\
\hline \multicolumn{5}{|c|}{ Age (re: 30-39) } \\
\hline $16-19$ & $0.41(2.18)$ & $1.05(0.12)$ & $0.51(1.35)$ & $2.56(1.77)$ \\
\hline $20-24$ & $1.43(1.22)$ & $1.16(0.55)$ & $0.92(0.18)$ & $1.82(1.34)$ \\
\hline $25-29$ & $1.12(0.36)$ & $0.40(2.92)$ & $0.54(1.30)$ & $0.80(0.47)$ \\
\hline $40-49$ & $0.36(3.34)$ & $0.84(0.58)$ & $0.73(0.69)$ & $1.00(0.00)$ \\
\hline $50+$ & $0.39(2.82)$ & $1.69(1.49)$ & $0.18(1.55)$ & $1.00(0.00)$ \\
\hline \multicolumn{5}{|c|}{ Education (re: Primary) } \\
\hline None & $0.88(0.43)$ & $0.66(1.34)$ & $0.97(0.05)$ & $2.47(1.39)$ \\
\hline Secondary & $0.69(1.81)$ & $0.94(0.29)$ & $1.25(0.69)$ & $0.68(1.21)$ \\
\hline Vocational & $0.47(1.60)$ & $0.61(0.77)$ & $1.52(0.76)$ & $0.27(2.11)$ \\
\hline Jr. College & $0.81(0.26)$ & $0.44(1.08)$ & $3.73(2.26)$ & $1.06(0.11)$ \\
\hline University & $1.01(0.01)$ & $0.29(1.59)$ & $3.19(1.62)$ & $0.28(2.25)$ \\
\hline \multicolumn{5}{|c|}{ Relation to Employment Office between i-1th and ith quarter } \\
\hline UB in both & reference & reference & reference & reference \\
\hline Exhaust & $1.32(1.92)$ & $1.82(2.31)$ & $1.65(2.04)$ & $1.89(1.24)$ \\
\hline No UB & $0.85(0.77)$ & $0.73(1.48)$ & $0.89(0.33)$ & $1.15(0.42)$ \\
\hline \multicolumn{5}{|c|}{ Household Composition } \\
\hline HH size & $0.97(0.26)$ & $0.93(0.59)$ & $1.18(1.17)$ & $1.28(1.69)$ \\
\hline \# children & $0.80(1.50)$ & $0.90(0.72)$ & $0.80(1.37)$ & $0.68(2.30)$ \\
\hline \# workers & $1.25(1.80)$ & $1.12(0.89)$ & $0.85(0.97)$ & $0.89(0.66)$ \\
\hline$\Delta$ workers & $1.43(1.48)$ & $1.04(0.16)$ & $0.65(1.27)$ & $1.76(1.61)$ \\
\hline \# unemp. & $1.33(2.21)$ & $1.12(0.99)$ & $1.50(2.43)$ & $0.86(0.85)$ \\
\hline$\Delta$ unemp. & $1.54(2.00)$ & $0.79(1.14)$ & $0.86(0.49)$ & $1.42(1.12)$ \\
\hline
\end{tabular}

Note: This table reports mulinomial logit regression results with four alternatives: Yes-Yes, Yes-No, No-Yes and No-No. For interpretation convenience the estimates of No-Yes transition is the estimation results with the No-No as omitted category, and those of Yes-No is the estimation results with the Yes-Yes as omitted category. The estimated odds ratios between the categories No-No and Yes-Yes are not reported since they are very similar to those in Table 1. Unsigned asymptotic t-statistics are reported in parentheses. 
Table 6: Comparison of Characteristics

between Not-Missing and Missing Samples

\begin{tabular}{|c|c|c|}
\hline & $\begin{array}{r}\text { NotMissing }^{\mathrm{a}} \\
(\mathrm{N}=5434) \\
\end{array}$ & $\begin{array}{r}\text { Missing }^{\mathrm{b}} \\
(\mathrm{N}=2794)\end{array}$ \\
\hline \multicolumn{3}{|c|}{$\%$ Not Missing and \% Missing by Nth Interview } \\
\hline 1st Interview & 100 & 0 \\
\hline 2nd Interview & 89.7 & 9.3 \\
\hline 3rd Interview & 83.6 & 16.4 \\
\hline 4th Interview & 77.5 & 22.5 \\
\hline 5th Interview & 73.1 & 26.9 \\
\hline 6th Interview & 69.7 & 30.3 \\
\hline \multicolumn{3}{|l|}{ By Gender } \\
\hline Male & 61.2 & 58.6 \\
\hline Female & 38.8 & 41.4 \\
\hline \multicolumn{3}{|c|}{ By Relation to Head of Household } \\
\hline Head & 26.1 & 31.3 \\
\hline Spouse & 14.9 & 16.3 \\
\hline Son/Daughter & 54.5 & 45.4 \\
\hline Other & 4.5 & 7.0 \\
\hline \multicolumn{3}{|l|}{ Age } \\
\hline $16-19$ & 16.4 & 12.3 \\
\hline $20-24$ & 24.9 & 23.9 \\
\hline $25-29$ & 15.4 & 22.5 \\
\hline $30-39$ & 20.5 & 23.8 \\
\hline $40-49$ & 13.8 & 10.0 \\
\hline $50+$ & 9.1 & 7.5 \\
\hline \multicolumn{3}{|l|}{ Education } \\
\hline None & 11.4 & 9.8 \\
\hline Primary & 30.7 & 28.9 \\
\hline Secondary & 45.3 & 47.1 \\
\hline Vocational & 5.9 & 5.3 \\
\hline University & 6.6 & 9.0 \\
\hline \multicolumn{3}{|l|}{ By Marital Status } \\
\hline Single & 56.5 & 52.2 \\
\hline Married & 41.2 & 43.8 \\
\hline Other & 2.3 & 4.0 \\
\hline
\end{tabular}

a: Observed in all six interviews.

b: Observed in first interview but missing in some subsequent interviews. 
Table 7: Attrition Rate by Migration Willingness

\begin{tabular}{|c|c|c|c|}
\hline & $\begin{array}{l}\text { Willing to move } \\
\text { for work? } \\
\text { at ith Interview }\end{array}$ & $\begin{array}{r}\% \text { Missing at } \\
\mathrm{i}+1 \text { th interview }\end{array}$ & $\begin{array}{r}\text { t-statistics } \\
\text { for equality }\end{array}$ \\
\hline \multirow[t]{2}{*}{ 1st Interview } & yes $(\mathrm{N}=2778)$ & 10.1 & 1.74 \\
\hline & no $(\mathrm{N}=3151)$ & 8.8 & \\
\hline \multirow[t]{2}{*}{ 2nd Interview } & yes $(\mathrm{N}=1825)$ & 8.9 & 1.87 \\
\hline & no $(\mathrm{N}=2108)$ & 7.3 & \\
\hline \multirow[t]{2}{*}{ 3rd Interview } & yes $(\mathrm{N}=1556)$ & 8.2 & 1.99 \\
\hline & no $(\mathrm{N}=1806)$ & 6.8 & \\
\hline \multirow[t]{2}{*}{ 4th Interview } & yes $(\mathrm{N}=1330)$ & 6.7 & 1.87 \\
\hline & no $(\mathrm{N}=1531)$ & 5.2 & \\
\hline \multirow[t]{2}{*}{ 5th Interview } & yes $(N=1304)$ & 7.4 & 1.46 \\
\hline & no $(\mathrm{N}=1583)$ & 5.1 & \\
\hline
\end{tabular}


Table 8: Estimated Result of Unemployment Duration

Sample: On-going Unemployment Duration at 1st Interview $<7$ months

\begin{tabular}{|c|c|c|}
\hline Covariates & Male $(\mathrm{N}=2327)$ & Female $(\mathrm{N}=1253)$ \\
\hline \multicolumn{3}{|c|}{ Migration Attitude at 1st Interview (re: negative) } \\
\hline Positive & $-0.34(2.37)$ & $-0.23(0.78)$ \\
\hline \multicolumn{3}{|c|}{ Relation to Head of Household (re: head) } \\
\hline Spouse, Head work & --- & $0.47(3.00)$ \\
\hline Spouse, head unem & --- & $0.20(1.07)$ \\
\hline Spouse, head inac & --- & $0.31(1.22)$ \\
\hline Child, head work & $0.34(3.65)$ & $0.23(1.32)$ \\
\hline Child, head unem & $-0.01(0.06)$ & $0.24(1.17)$ \\
\hline Child, head inac & $0.54(6.80)$ & $0.32(1.90)$ \\
\hline Others & $0.08(0.41)$ & $0.27(0.63)$ \\
\hline \multicolumn{3}{|l|}{ Age (re: 30-39) } \\
\hline $16-19$ & $-0.25(2.17)$ & $-0.25(1.58)$ \\
\hline $20-24$ & $-0.05(0.56)$ & $0.01(0.11)$ \\
\hline $25-29$ & $-0.11(1.37)$ & $-0.02(0.19)$ \\
\hline $40-49$ & $0.20(2.53)$ & $0.12(1.00)$ \\
\hline $50+$ & $0.47(4.67)$ & $0.21(0.94)$ \\
\hline \multicolumn{3}{|l|}{ Education (re: Primary) } \\
\hline None & $-0.10(1.26)$ & $-0.19(1.33)$ \\
\hline Secondary & $0.05(0.87)$ & $-0.00(0.07)$ \\
\hline Vocational & $-0.04(0.30)$ & $-0.01(0.07)$ \\
\hline Jr. College & $0.19(0.80)$ & $-0.32(1.51)$ \\
\hline University & $-0.11(0.69)$ & $-0.01(0.07)$ \\
\hline \multicolumn{3}{|c|}{ Occupation at Prior Job (re: never worked) } \\
\hline Agricultural workers & $-0.84(7.69)$ & $-0.86(5.65)$ \\
\hline Managers & $-0.86(4.81)$ & $-0.43(1.73)$ \\
\hline Professionals & $-0.26(1.65)$ & $-0.76(5.00)$ \\
\hline Assistant Prof. & $-0.36(3.42)$ & $-0.39(3.70)$ \\
\hline Skilled manual workers & $-0.45(4.58)$ & $-0.59(4.55)$ \\
\hline Unskilled workers & $-0.47(4.42)$ & $-0.44(3.04)$ \\
\hline
\end{tabular}

Relation to Public Employment Office (re: registered but not receiving UB)

Receiving subsidy

$0.18(1.94)$

$0.21(1.81)$ 
Not registered

$0.10(1.17)$

$0.12(1.20)$

Year (re: 1992)

1993

$0.00(0.03)$

0.16 (1.94)

1994

$-0.13(2.14)$

$0.05(0.60)$

Local labour market condition

Unemployment rate

$0.47(3.20)$

$0.14(0.68)$

Vacancy rate

-0.18 (0.99)

-0.33 (1.38)

Correlation

$0.19(2.13)$

$0.11(0.60)$

Note: The estimation results of the equation of migration willingness are not reported here since they were virtually the same as those reported in Table 1 . Neither are the threshold parameters included. Unsigned asymptotic t-statistics are reported in parentheses. 
Appendix 1: Willing to Move for Work?

Multimonial Logistic Regression (Data: EPA 1992/I-1994/IV)

(Reference: Negative; t-statistics in parenthesis)

\begin{tabular}{|c|c|c|c|c|}
\hline \multirow[b]{2}{*}{ Variables } & \multicolumn{2}{|c|}{ Male $(\mathrm{N}=3097)$} & \multicolumn{2}{|c|}{ Female $(\mathrm{N}=1631)$} \\
\hline & Positive & Undecided & Positive & Undecided \\
\hline \multicolumn{5}{|c|}{ Relation to Head of Household } \\
\hline Head & reference & reference & reference & reference \\
\hline Spouse, head work & --- & --- & $2.26(3.77)$ & $0.58(1.57)$ \\
\hline Spouse, head unem & --- & --- & $0.74(0.78)$ & $1.08(0.19)$ \\
\hline Spouse, head inac & --- & --- & $0.81(0.35)$ & $0.31(1.42)$ \\
\hline Child, head work & $2.30(3.77)$ & $1.01(0.06)$ & $1.33(0.67)$ & $1.38(0.76)$ \\
\hline Child, head unem & $1.96(2.35)$ & $1.19(0.56)$ & $1.26(0.48)$ & $1.30(0.55)$ \\
\hline Child, head inac & $2.53(4.98)$ & $1.31(1.33)$ & $1.34(0.72)$ & $2.05(1.79)$ \\
\hline Others & $1.01(0.05)$ & $0.96(0.14)$ & $1.02(0.03)$ & $2.53(1.88)$ \\
\hline \multicolumn{5}{|l|}{$\underline{\text { Age }}$} \\
\hline $16-19$ & $0.43(3.71)$ & $1.03(0.14)$ & $0.45(2.56)$ & $0.52(2.21)$ \\
\hline $20-24$ & $1.27(1.35)$ & $1.72(2.76)$ & $1.09(0.33)$ & $0.79(0.87)$ \\
\hline $25-29$ & $1.39(2.00)$ & $1.43(1.95)$ & $1.04(0.14)$ & $1.02(0.09)$ \\
\hline $30-39$ & reference & reference & reference & reference \\
\hline $40-49$ & $0.68(2.41)$ & $0.91(0.53)$ & $0.51(2.05)$ & 0.74 (1.01) \\
\hline $50+$ & $0.34(5.11)$ & $0.54(2.78)$ & $0.13(2.53)$ & $0.45(1.34)$ \\
\hline \multicolumn{5}{|l|}{ Education } \\
\hline None & $0.96(0.27)$ & $1.00(0.05)$ & $0.80(0.58)$ & $0.80(0.57)$ \\
\hline Primary & reference & reference & reference & reference \\
\hline Secondary & $1.10(0.80)$ & $1.09(0.67)$ & $1.18(0.90)$ & $1.38(1.75)$ \\
\hline Vocational & $1.31(1.12)$ & $0.94(0.23)$ & $1.90(2.37)$ & $1.29(0.88)$ \\
\hline Jr. College & $1.57(1.05)$ & $0.88(0.23)$ & $4.98(4.67)$ & $2.07(2.02)$ \\
\hline University & $5.92(4.46)$ & $2.69(2.37)$ & $8.52(5.88)$ & $2.44(2.28)$ \\
\hline Ever Worked & $1.77(2.93)$ & $1.21(0.97)$ & $1.65(2.53)$ & $0.85(0.84)$ \\
\hline \multicolumn{5}{|c|}{ Relation to Public Employment Office (INEM) } \\
\hline Receiving subsidy & $0.95(0.30)$ & $1.01(0.05)$ & $1.10(0.36)$ & $1.44(1.40)$ \\
\hline Only registered & $1.15(0.79)$ & $0.99(0.04)$ & $1.10(0.43)$ & $1.34(1.30)$ \\
\hline Not registered & reference & reference & reference & reference \\
\hline \multicolumn{5}{|c|}{ Household Composition } \\
\hline Household Size & $1.04(0.95)$ & $1.00(0.12)$ & $0.97(0.52)$ & $0.91(1.35)$ \\
\hline \# workers & $0.93(0.95)$ & $1.04(0.55)$ & $1.15(1.27)$ & $1.05(0.46)$ \\
\hline \# unemployed & $1.34(3.86)$ & $1.02(0.21)$ & $1.02(0.16)$ & $1.03(0.25)$ \\
\hline Children $0-6$ years & $1.09(0.71)$ & $1.01(0.08)$ & $0.77(1.06)$ & $0.86(0.67)$ \\
\hline Children 7-15 & $0.97(0.41)$ & $0.97(0.31)$ & $0.77(1.44)$ & $0.70(1.98)$ \\
\hline
\end{tabular}




\begin{tabular}{|c|c|c|c|c|}
\hline \multicolumn{5}{|l|}{ Year (re: 1992) } \\
\hline 1993 & $1.12(0.99)$ & $1.05(0.40)$ & $1.11(0.64)$ & $1.18(0.99)$ \\
\hline 1994 & $1.17(1.30)$ & $1.15(1.12)$ & $1.11(0.61)$ & $1.02(0.10)$ \\
\hline \multicolumn{5}{|c|}{ Local Economy Condition } \\
\hline Log unemp. rate & $1.34(1.50)$ & $1.85(3.09)$ & $1.30(0.97)$ & $2.87(3.99)$ \\
\hline Log vacancy rate & $0.56(2.60)$ & $0.70(1.47)$ & $0.95(0.18)$ & $0.84(0.55)$ \\
\hline Lg real wage & $1.65(0.61)$ & $2.71(1.17)$ & $7.36(1.88)$ & $3.17(1.09)$ \\
\hline Log house price & $0.37(2.61)$ & $1.21(0.50)$ & $0.21(2.88)$ & $2.07(1.51)$ \\
\hline Model Chi-square & 715.38 & & 535.62 & \\
\hline
\end{tabular}

Unsigned asymptotic t-statistics in parentheses. Also included (but not reported) are the region variables. 
Appendix 2: Simple Probit Estimation of Unemployment Duration

\begin{tabular}{|c|c|c|}
\hline Covariates & Male $(\mathrm{N}=2327)$ & Female $(\mathrm{N}=1253)$ \\
\hline \multicolumn{3}{|c|}{ Migration Attitude at 1st Interview (re: negative) } \\
\hline Positive & $-0.05(0.97)$ & $-0.06(0.80)$ \\
\hline \multicolumn{3}{|c|}{ Relation to Head of Household (re: head) } \\
\hline Spouse, Head work & --- & $0.50(3.26)$ \\
\hline Spouse, head unem & --- & $0.21(1.13)$ \\
\hline Spouse, head inac & --- & $0.32(1.27)$ \\
\hline Child, head work & $0.29(3.24)$ & $0.19(1.13)$ \\
\hline Child, head unem & $-0.08(0.66)$ & $0.21(1.07)$ \\
\hline Child, head inac & $0.48(6.42)$ & $0.29(1.71)$ \\
\hline Others & $0.11(1.03)$ & $0.18(0.74)$ \\
\hline \multicolumn{3}{|l|}{ Age (re: 30-39) } \\
\hline $16-19$ & $-0.16(1.43)$ & $-0.21(1.51)$ \\
\hline $20-24$ & $-0.04(0.48)$ & $0.01(0.12)$ \\
\hline $25-29$ & $-0.14(1.72)$ & $-0.03(0.25)$ \\
\hline $40-49$ & $0.24(3.03)$ & $0.13(1.06)$ \\
\hline $50+$ & $0.55(5.86)$ & $0.24(1.07)$ \\
\hline \multicolumn{3}{|l|}{ Education (re: Primary) } \\
\hline None & $-0.11(1.35)$ & $-0.18(1.20)$ \\
\hline Secondary & $0.05(0.92)$ & $-0.01(0.06)$ \\
\hline Vocational & $-0.03(0.31)$ & $-0.03(0.23)$ \\
\hline Jr. College & $0.18(0.85)$ & $-0.37(2.12)$ \\
\hline University & $-0.15(0.99)$ & $-0.08(0.49)$ \\
\hline \multicolumn{3}{|c|}{ Occupation at Prior Job (re: never worked) } \\
\hline Agricultural workers & $-0.84(7.42)$ & $-0.87(5.86)$ \\
\hline Managers & $-0.82(4.86)$ & $-0.43(1.65)$ \\
\hline Professionals & $-0.21(1.28)$ & $-0.76(5.06)$ \\
\hline Assistant Prof. & $-0.34(3.20)$ & $-0.38(3.86)$ \\
\hline Skilled manual workers & $-0.43(4.15)$ & $-0.59(4.56)$ \\
\hline Unskilled workers & $-0.45(4.12)$ & $-0.44(2.83)$ \\
\hline
\end{tabular}

$\underline{\text { Relation to Public Employment Office (re: registered but not receiving UB) }}$ Receiving subsidy $0.19(2.05)$ $0.20(1.70)$ 


\begin{tabular}{lcc}
$\begin{array}{l}\text { Not registered } \\
\text { Year (re: 1992) } \\
1993\end{array}$ & $0.10(1.17)$ & $0.11(1.09)$ \\
1994 & $0.00(0.06)$ & $0.16(1.91)$ \\
$\underline{\text { Local labour market condition }}$ & $-0.12(2.03)$ & $0.05(0.63)$ \\
Unemployment rate & & \\
Vacancy rate & $0.19(3.03)$ & $0.05(0.66)$ \\
\hline
\end{tabular}

Note: Threshold parameters are not included. Unsigned asymptotic t-statistics are reported in parentheses. 